\title{
Desarrollo de las competencias de indagación y explicación a través de prácticas de aula basadas en la enseñanza para la comprensión
}

\section{Development of inquiry and explanation skills through classroom practices based on teaching for understanding}

DOI: http://dx.doi.org/10.17981/cultedusoc.11.2.2020.06

Recibido: 20 de diciembre de 2019 Aceptado: 02 de abril de 2020 Publicado: 09 de julio de 2020

José Eduardo Cifuentes Garzón

Secretaría de Educación de Cundinamarca. La Palma Cundinamarca (Colombia)

josecifuentes1980@gmail.com

Luz Marina Cortés Beltran

IED Ricardo González. Subachoque (Colombia)

luzmacobe@hotmail.com

Nidia Yolanda Garzón Mora

IED Ricardo González. Subachoque (Colombia)

nidiagarzon@gmail.com

Diana Patricia González Pulido

IED Ricardo González. Subachoque (Colombia) dianagonzalez-210@hotmail.com

Para citar este artículo:

Cifuentes, J., Cortés, L., Garzón, N. y González, D. (2020). Desarrollo de las competencias de indagación y explicación a través de prácticas de aula basadas en la enseñanza para la comprensión. Cultura, Educación y Sociedad, 11(2). 87-109. DOI: http://dx.doi. org/10.17981/cultedusoc.11.2.2020.06

\section{Resumen}

Se requiere resignificar la enseñanza desde la implementación de estrategias innovadoras para el desarrollo del pensamiento científico en los estudiantes de primaria. Desde este referente el objetivo del artículo es describir las transformaciones en las prácticas de aula a partir de la implementación del marco de la enseñanza para la comprensión, en el desarrollo de las competencias de indagación y explicación de fenómenos en estudiantes de primero y quinto de educación básica primaria. El estudio es de enfoque cualitativo con alcance descriptivo y con el diseño de la Investigación Acción Pedagógica. Se logró documentar los cambios en la enseñanza ocurridos con la planeación e implementación de unidades didácticas para el fortalecimiento de la indagación y la explicación de fenómenos. Como conclusión destaca que las dinámicas de aula influyen directamente en el aprendizaje, al incorporar nuevas estrategias pedagógicas los estudiantes son protagonistas del conocimiento al investigar su mundo circundante.

Palabras clave: Prácticas de aula; competencias de indagación y explicación de fenómenos; enseñanza para la comprensión

\begin{abstract}
It is required to resignify the teaching from the implementation of innovative strategies for the development of scientific thought in primary school students. From this point of view, the objective of the article is to describe the transformations in classroom practices from the implementation of the teaching framework for understanding, in the development of the powers of inquiry and explanation of phenomena in students of first and fifth education primary basic. The study is a qualitative approach with a descriptive scope and with the design of the Pedagogical Action Research. It was possible to document the changes in teaching that occurred with the planning and implementation of didactic units to strengthen the investigation and the explanation of phenomena. In conclusion, he highlights that classroom dynamics directly influence learning, by incorporating new pedagogical strategies, students are protagonists of knowledge when investigating their surrounding world.
\end{abstract}

Keywords: Classroom practices; inquiry skills and explanation of phenomena; teaching for understanding 


\section{INTRODUCCIÓN}

En el presente artículo se reportan los hallazgos de una investigación que surgió de la necesidad de resignificar las prácticas de aula desde las nuevas experiencias y de la creación de estrategias innovadoras orientadas a un mejoramiento de habilidades, competencias, aprendizajes y al desarrollo del pensamiento científico de los estudiantes de primero y quinto de primaria de la Institución Educativa Departamental Ricardo González del municipio de Subachoque Cundinamarca-Colombia. En esta perspectiva, el marco de la enseñanza para la comprensión, el cual "se diseña para orientar las prácticas docentes y las estrategias pedagógicas, así como la reflexión continua del trabajo en el aula” (Villamizar, Montero, González y Castillo, 2019, p. 40), se convirtió en una posibilidad para mejorar los procesos de enseñanza y de aprendizaje y contribuir al desarrollo de prácticas pedagógicas de calidad.

De acuerdo con lo anterior, esta investigación se orientó por la pregunta: ¿De qué manera la implementación del marco de enseñanza para la comprensión fortalece las prácticas de aula para el desarrollo de las competencias de indagación y explicación de fenómenos en los estudiantes de básica primaria? En consecuencia, se formuló como objetivo general describir las transformaciones en las prácticas de aula a partir de la implementación del marco de la enseñanza para la comprensión, en el desarrollo de las competencias de indagación y explicación de fenómenos en estudiantes de primero y quinto de educación básica primaria.

Para lograr lo anterior, se diseñaron e implementaron los siguientes objetivos específicos: determinar el nivel de desarrollo de las competencias de indagación y explicación de fenómenos de los estudiantes a partir de los resultados de los tres últimos años de aplicación de las pruebas saber externas e internas. Establecer la incidencia de las prácticas pedagógicas en el aprendizaje de las competencias de indagación y explicación de fenómenos en los estudiantes. Implementar unidades en el marco de la enseñanza para la comprensión con el propósito de fortalecer las competencias de indagación y explicación de fenómenos en estudiantes y analizar las transformaciones de las prácticas pedagógicas desde el marco de la enseñanza para la comprensión en el desarrollo de los procesos de enseñanza de las competencias de indagación y explicación de fenómenos.

Con el desarrollo de los objetivos mediante la Investigación Acción Pedagógica, se pudo evidenciar como las dinámicas de aula favorecen el uso de estrategias didácticas, las cuales inciden de forma positiva en la construcción de nuevos conocimientos. Estas se van puliendo a lo largo del desarrollo de las diferentes actividades y conllevan a fortalecer las habilidades en los estudiantes y a la construcción de criterios claros con el fin de motivarlos a que adopten una postura crítica frente a nuevas realidades por enfrentar.

Los aportes de la Investigación Acción Pedagógica fueron fundamentales para el análisis de las prácticas pedagógicas, al darle una mayor resignificación y abordaje a las situaciones presentadas en el aula y se generaron momentos de cambio y transformación en los procesos de enseñanza y aprendizaje. Además, con esta investigación se posibilitó la articulación del contexto al colegio y la participación significativa de los estudiantes, dada la experiencia adquirida en la labor diaria con sus padres y con los trabajos escolares, lo cual es importante para ayudar a argumentar, comprender y reflexionar con mayor intensidad las nuevas experiencias que los inquietan; permitiéndose así el diálogo con otros al aprender a preguntar, escuchar y comunicar, como se demuestra en los siguientes apartados. 


\section{Fundamentos TeóRIcos}

En lo teórico se abordaron como categorías la enseñanza y el aprendizaje de las ciencias naturales, el desarrollo de competencias en las ciencias naturales, el marco de la enseñanza para la comprensión y las prácticas de aula:

\section{Enseñanza y aprendizaje de las ciencias naturales}

La enseñanza de las ciencias naturales permite vincular los procesos y las formas como los docentes median el aprendizaje de sus estudiantes, con el fin de desarrollar el pensamiento científico y a partir de allí generar competencias, destrezas y habilidades acordes a los intereses y expectativas requeridas por cada disciplina en la sociedad actual. Según lo expuesto por Harlen (2010), las intervenciones de los profesores en el proceso de aprendizaje de los estudiantes se llevan a cabo en el diseño de actividades y el acompañamiento en ellas. Es decir, "los docentes se prestan como acompañantes y guías en el proceso de enseñanza-aprendizaje de las ciencias" (Torres y Sánchez, 2019, p. 2). Además, es fundamental los materiales con los que interactúan para facilitar la comprensión, el diálogo generado a partir de la experimentación y al crear las condiciones necesarias para producir los aprendizajes.

Es importante estimular en los estudiantes el análisis detallado de aquello que observan para ayudar a los niños a desarrollar sus ideas, cambiarlas o transformarlas. En este sentido, Harlen (2010) enfatiza en la necesidad de invitar a los niños a comprobar sus ideas, ampliar la experiencia infantil, fomentar el uso de los términos científicos que les permita revisar la experiencia anterior en relación con ideas nuevas, siendo agentes de cambio de modo que la comprensión de los fenómenos sea esencial para la permanente evolución de sus nuevos conocimientos. En este orden de ideas, para Peña, Cevallos y Espinoza (2019), el profesor debe emplear metodologías centradas en el desarrollo de mecanismos de aprendizaje y habilidades investigativas en los estudiantes.

Según Torres y Sánchez (2019, p. 2) "se necesitan docentes que fomenten el pensamiento crítico, docentes que involucren a los estudiantes de manera directa, realizando actividades o dinámicas que los lleven a pensar en lo que están haciendo". En este mismo sentido, de acuerdo con Harlen (2010), en el desarrollo del pensamiento, el papel del profesor debe caracterizarse por proporcionar espacios donde los estudiantes hagan observaciones amplias y detalladas, tengan en cuenta aspectos como los objetos o materiales interesantes para observar en los cuales los estudiantes tengan la evidencia de sus propios sentidos, formulen preguntas, hallen la respuesta a través de las prácticas y tengan experiencias concretas como base de su pensamiento y sean capaces de comprobar las ideas, dar el tiempo suficiente para la socialización de los conocimientos, escuchar a los demás, argumentar sobre las diferencias y refinar sus propios puntos de vista de forma crítica.

Así las cosas, en la enseñanza y en el aprendizaje de las ciencias naturales se deben diseñar unidades y secuencias didácticas que lleven a los estudiantes a pensar, a desarrollar comprensiones profundas, a explorar y a transferir el conocimiento al contexto cotidiano. En este sentido, las actividades pedagógicas deben estar destinadas al desarrollo de "conocimientos y habilidades no solo en contextos reales y cercanos a los estudiantes, sino a través 
de situaciones retadoras en las que deberán hacer uso creativo y flexible de sus saberes, aportando así al desarrollo de sus competencias" (Angarita, 2018, p. 149), de tal manera que se pueda evidenciar como "los estudiantes emplean el razonamiento, la argumentación y el pensamiento crítico. En definitiva, desarrollen la capacidad de observar, formular preguntas y proponer explicaciones (hipotetizar)" (García y Pérez, 2016, pp. 117-118).

\section{Desarrollo de competencias en las ciencias naturales}

De acuerdo con Véliz, Díaz y Rodríguez (2015), las competencias son un conjunto de conocimientos que facilitan la integración del saber, es decir los conocimientos; del saberhacer, referidas a las habilidades y capacidades; y del saber-ser, relacionadas con valores y actitudes. Varios autores han realizado aproximaciones a una concepción de las competencias científicas. Gómez (2018) "infiere que este tipo de competencia representa el conjunto de conocimientos, actitudes, habilidades, destrezas necesarias para llevar a cabo una tarea determinada en diferentes contextos, educativos, social y académico" (p. 469). Por tanto, es necesario desarrollar en los estudiantes competencias que les permitan aprender y desaprender en el transcurso de la vida, a fin de ajustarse a las situaciones y hechos en constantes cambios.

Para Hernández (2005), las competencias científicas son "un conjunto de saberes, capacidades y disposiciones que hacen posible actuar e interactuar de manera significativa en situaciones en las cuales se requiere producir, apropiar o aplicar comprensiva y responsablemente los conocimientos científicos" (p. 21). Estas competencias generan "necesidades de habilidades como la capacidad de indagar, valorar pruebas, y realizar análisis crítico que se ha propuesto que pueden desarrollarse desde distintos enfoques metodológicos" (DomènechCasal, 2019, p. 86). Así las cosas, "En la enseñanza de las ciencias naturales conviene definir ciertas competencias específicas que describen de manera precisa la comprensión de los fenómenos y del quehacer en el área” (Rojas, Rosas y Sanabria, 2017, pp. 25-26).

Las competencias específicas de ciencias naturales consideradas importante para desarrollar en el aula de clase, según el Instituto Colombiano para el Fomento de la Educación Superior (ICFES, 2007), son: identificar (Capacidad para reconocer y diferenciar fenómenos, representaciones y preguntas pertinentes sobre estos fenómenos), indagar (Capacidad para plantear preguntas y procedimientos adecuados y para buscar, seleccionar, organizar e interpretar información relevante para dar respuesta a esas preguntas), explicar (Capacidad para construir y comprender argumentos, representaciones o modelos que den razón de fenómenos), comunicar (Capacidad para escuchar, plantear puntos de vista y compartir conocimiento), trabajar en equipo. (Capacidad para interactuar productivamente asumiendo compromisos), disposición para aceptar la naturaleza abierta, parcial y cambiante del conocimiento y disposición para reconocer la dimensión social del conocimiento y para asumirla responsablemente (p. 18).

En el presente estudio se abordaron únicamente las competencias de indagación y explicación. La competencia de indagar "incluye la acción planeada, orientada a la búsqueda de información que ayude a establecer la validez de una respuesta preliminar. Esta acción puede tener distintos grados de elaboración" (ICFES, 2007, p. 19). Esto "implica la disposición, por parte del sujeto, de un conocimiento acerca del cual reflexionar para hacer 
consciencia del mismo y para relacionarlo con los procesos de indagación científica" (Icfes, 2007, p. 20). Por su parte, la competencia de explicar "consiste en la producción de razones sobre el porqué de un fenómeno, sobre sus causas y sobre las relaciones que guarda con otros fenómenos, desde distintos marcos de referencia" (ICFES, 2007, p. 20).

\section{Enseñanza para la comprensión}

Se denomina comprensión a una perspectiva de desempeño. Según Blythe (1999), "la comprensión incumbe a la capacidad de hacer con un tópico una variedad de cosas que estimulan el pensamiento, tales como explicar, demostrar, dar ejemplos, generalizar, y establecer analogías" (p. 39). De acuerdo con Cifuentes (2019), "El marco de la enseñanza para la comprensión se ha venido consolidando desde las experiencias de los mismos profesores de aula, quienes reflexionan sobre su quehacer e intervienen para lograr mejores aprendizajes" (p. 19), convirtiéndose en "una opción valiosa para transformar nuestras prácticas educativas, pues permite desarrollar comprensiones profundas, promueve el aprendizaje significativo y crea verdaderas culturas de pensamiento en el aula y fuera de ella” (Cifuentes, 2015, p. 80).

Blythe (1999) establece dentro del marco de la enseñanza para la comprensión cuatro momentos clave para potencializar los procesos de enseñanza, aprendizaje y desarrollo del pensamiento. En primera instancia se enmarcan los Tópicos generativos, concebidos como centrales para una o más disciplinas o dominios y resultan llamativos para los estudiantes; varían de acuerdo al contexto social, cultural y a sus intereses; deben ser interesantes para los docentes, pues el interés, manifestado frente a un asunto, servirá de modelo para los estudiantes; de igual manera tienden a ser accesibles, al establecer los recursos apropiados, las estrategias y actividades promotoras de la comprensión y la conexión con experiencias previas.

Otro elemento planteado dentro de la enseñanza para la comprensión, según Blythe (1999), son las metas de comprensión, las cuales se presentan de dos formas, las correspondientes a una unidad donde se describe aquello que debe hacer el estudiante con un tópico generativo. Así mismo, las metas de comprensión abarcadoras corresponden a los tópicos para un curso, denominadas también hilos conductores, en los cuales se especifican los logros a alcanzar a través de su trabajo. En las metas de comprensión se identifican los conceptos, los procesos y las habilidades a desarrollar.

Dentro del mismo marco, Blythe (1999) plantea los desempeños de comprensión, concebidos como actividades de aprendizaje, las cuales tienen en cuenta la aplicación de los conocimientos previos en situaciones diferentes para llegar a la comprensión del tópico de la unidad. En este punto, los estudiantes expanden y aplican saberes, muestran sus comprensiones y hacen su pensamiento visible. Los desempeños de comprensión se presentan de manera secuencial, constituidos por tres etapas: La primera denominada la exploración de tópicos, espacio en donde los estudiantes utilizan sus ideas y experiencias para formular preguntas significativas sobre problemas específicos de áreas determinadas; en seguida se encuentra la investigación dirigida, en este momento las habilidades y conceptos del estudiante sobre esta disciplina permiten solucionar los conflictos presentados al abordar los materiales y conceptos de la misma; la última y tercera etapa denominada proyecto 
personal de síntesis, consiste en el trabajo final elaborado por los estudiantes acerca de un tópico generativo, exige hacer uso de los aprendizajes adquiridos para darle sentido a lo comprendido por el estudiante (Blythe, 1999).

De acuerdo con lo anterior, se considera la enseñanza para la comprensión, "pertinente para facilitar al maestro la organización de estrategias de acuerdo a su asignatura, contenidos curriculares y a la vez los intereses y necesidades de los estudiantes y así el quehacer pedagógico recobre sentido" (Suárez, Hernández, Méndez, Arguello y Garzón, 2020, p. 6). Además, la secuencia didáctica de este marco facilitó los procesos de aprendizaje, de desarrollo del pensamiento y de enseñanza de los estudiantes de la Institución Educativa Departamental Ricardo González de Subachoque Cundinamarca al fortalecer los desempeños y las competencias de indagación y explicación de fenómenos como se puede evidenciar en el apartado de los resultados.

\section{Prácticas de aula}

En la actualidad se exigen prácticas de aula innovadoras, en las cuales se mejore el clima escolar y se genere en los estudiantes una cultura de aprendizaje significativo para lograr indagar, explicar, defender sus propios puntos de vista, poder transformar y solucionar las problemáticas presentes en el entorno. Tal como lo afirma Samacá (2015), las prácticas pedagógicas se configuran como "el escenario de posibilidades para construir nuevas formas de mediación entre el conocimiento disciplinar y la acción en el campo de la praxis, desde la negociación cultural y el diálogo, alrededor de la exploración de los contextos" (p. 20).

En concordancia con lo anterior, es indispensable que el docente tome su tiempo para repensar sobre su propia práctica. Dicha reflexión tiene como fin generar nuevos conocimientos o motivar el trabajo colaborativo entre todos los miembros de la comunidad educativa y en este sentido lograr un impacto positivo en el aprendizaje de los estudiantes, al aplicar diferentes estrategias para el logro de un aprendizaje reflexivo y efectivo, donde asuma un papel de mediador, orientador, guía e investigador de los procesos al interior del aula.

En este sentido, es necesario generar espacios de cuestionamiento y formulación de interrogantes como: ¿Qué aprendieron los estudiantes?, ¿Qué aspectos de la clase fueron buenos?, ¿Qué no salió tan bien? y ¿Qué aspectos tengo que mejorar?, que permitan al docente hacer un proceso constructivo y crítico de su enseñanza, y lo lleve a replantear sus procesos y metodologías. En esta misma línea, Burgos y Cifuentes (2015), conciben la práctica pedagógica como “... el escenario perfecto en el cual confluye el saber disciplinar del profesor, sus estrategias didácticas, las relaciones de poder en las interacciones con los distintos actores educativos y el querer o ideales que enmarcan su labor" (p. 119).

Por lo anterior, la presente investigación surgió de las dinámicas y realidades vivenciadas dentro del aula, donde el maestro es capaz de cooperar, a partir de su conocimiento disciplinar y didáctico en la construcción de los aprendizajes de los estudiantes de forma clara y coherente, sin desligar la influencia de sus contextos y entornos socioculturales, pues este aspecto actúa como un factor determinante y crucial para las acciones que tienen lugar dentro del aula. 


\section{MetodoloGía}

La investigación tuvo lugar en el municipio de Subachoque Cundinamarca, donde está ubicada la Institución Educativa Departamental Ricardo González. Esta institución es de carácter oficial de educación formal, cuenta con 1900 estudiantes en jornada única, organizada en los siguientes niveles: preescolar, educación básica primaria, básica secundaria, media y 110 estudiantes en educación para adultos; está conformada por 13 sedes, entre ellas tres urbanas, bachillerato, primaria y preescolar y 10 sedes rurales de las cuales cinco son unitarias.

Dentro de los grupos participantes en la investigación, se encuentran la sede de primaria urbana y la sede rural Canica Baja con los cursos primero y quinto. El grado 102 de la sede B urbana conformada por 33 estudiantes (15 niños y 18 niñas), con edades entre los 5 y 7 años. El grado 501 cuenta con 26 estudiantes (12 niñas y 14 niños), con edades entre 9 y 13 años. La Escuela Canica Baja está ubicada a 5 kilómetros del casco urbano. Dentro del grupo de participantes se encuentra el grado primero con 7 estudiantes (3 niñas y 4 niños) con edades de 5 y 6 años y grado quinto con 10 estudiantes (4 niñas y 6 niños) con edades de 9 y 11 años.

La investigación fue de tipo cualitativo, la cual según Hernández, Fernández y Baptista (2014), "se enfoca en comprender los fenómenos, explorándolos desde la perspectiva de los participantes en un ambiente natural y en relación con su contexto" (p. 5). Por lo tanto, el aula y las interacciones que allí tienen lugar son el objeto de investigación, donde se observa y se reflexiona de forma permanente los procesos de enseñanza, aprendizaje y los desempeños logrados por los estudiantes en el área de ciencias naturales en lo referido a las competencias de indagación y explicación de fenómenos.

El proyecto de investigación estaba concebido mediante la metodología InvestigaciónAcción- Pedagógica. Para Elliot (2000), la investigación-acción "se relaciona con los problemas prácticos cotidianos experimentados por los profesores... Puede ser desarrollada por los mismos profesores o por alguien a quien ellos se lo encarguen" (p. 5). Es decir, con este tipo de investigación se "obliga, gracias a sus ciclos recursivos de abordaje de los objetivos de investigación, a reflexionar acerca de lo que se hace mientras se hace" (Paukner y Sandoval, 2018, p. 507). Al respecto, para Fernández y Johnson (2015, p. 103) "La investigación-acción educativa concibe a los docentes como co-constructores de conocimiento, profesionales capaces de reflexionar críticamente sobre sus prácticas y mejorarlas y a su formación como un proceso dialógico de reflexión y acción”. En esta perspectiva, se pretendió reflexionar sobre las problemáticas del quehacer pedagógico de los profesores y de esta manera replantear estrategias que permitieran dar una mirada más profunda a los procesos educativos en el aula para darles una mayor resignificación y abordaje.

De acuerdo con Ávila (2005), la Investigación Acción Pedagógica "busca explorar las intimidades de las prácticas pedagógicas, en el ámbito de la escuela” (p. 505). Para lograr esto, el proceso investigativo del proyecto conllevó las fases de diagnóstico, intervención de las prácticas de aula y validación de la efectividad:

Fase I. Diagnóstico y diseño de la investigación: En esta etapa se llevaron a cabo las revisiones pertinentes de los resultados de las pruebas saber en lo referido a las competencias de indagación y explicación de fenómenos, cuyos desempeños fueron bajos. Así mismo, se llevó a 
cabo una reflexión profunda de las prácticas pedagógicas, las metodologías de enseñanza, el conocimiento didáctico empleado en el desarrollo de las clases y el impacto que ejerce en los estudiantes, a partir de la matriz de evaluación maestro 20/25 del Ministerio de Educación Nacional de Colombia. De esta manera, se planteó la delimitación y definición del tema a investigar y los intereses que se han desarrollado para plantear los objetivos generales y específicos. Se identificó la situación precisa y las diversas hipótesis en el grupo de trabajo y se estableció también la pregunta inicial a desarrollar en las etapas siguientes del proyecto.

En esta etapa, también se establecieron las diversas categorías que fueron de interés para investigar en la población, así mismo los procedimientos para la recolección de la información y el análisis de datos. Se distribuyeron las tareas a desarrollar por los integrantes del grupo de investigación. Se caracterizaron los grupos objeto de estudio y la evaluación de las prácticas pedagógicas para determinar fortalezas y aspectos a mejorar con el fin de direccionar la intervención en el aula de clase a partir de la descripción de los diarios de campo, recolección de datos y la observación de la mediación del aprendizaje.

Fase II. Intervención en las prácticas de aula: En este momento se diseñaron y aplicaron las unidades en el marco de la enseñanza para la comprensión, las cuales incluían los diferentes elementos: tópico generativo, metas de comprensión (conocimiento, método, propósito y comunicación), desempeños de comprensión (exploración del tópico, investigación guiada y proyecto final de síntesis). La recolección de la información se hizo mediante los diarios de campo, entrevistas, talleres con rutinas de pensamiento, registros fotográficos y videos, lo cual permitió documentar todo el proceso de implementación de las unidades.

Fase III. Validación, interpretación y reflexión: Se analizaron los resultados obtenidos. Se hizo una valoración de la intervención referida en la fase anterior, pudiéndose determinar las transformaciones ocurridas en las prácticas pedagógicas de los docentes investigadores. Esta fase, adicionalmente, permitió escribir las conclusiones, el informe final de la investigación y la divulgación de los hallazgos en eventos académicos.

Según Martínez (2014), la Investigación Acción Pedagógica, con la reflexión permanente y la documentación sistemática de las prácticas de aula se aporta al mejoramiento de las escuelas y a la construcción del conocimiento académico. Por tal razón, para llevar a cabo la investigación, se emplearon las siguientes técnicas e instrumentos de recolección de información, referenciados por Páramo (2011), con el fin de tener unos registros que dieran cuenta de las condiciones, características, procesos y resultados de los cambios en la intervención pedagógica:

Matriz de evaluación de la práctica pedagógica maestro 20/25: Esta rúbrica contiene las directrices establecidas por el Ministerio de Educación Nacional para evaluar la práctica de aula. En esta se despliega el criterio de evaluación, componente y aspecto a evaluar, seguido a esto, los niveles definidos y la descripción de la práctica pedagógica y educativa correspondiente. Las investigadoras caracterizaron sus prácticas iniciales a partir de este instrumento. Con relación a los estudiantes, se utilizó la matriz de análisis de las pruebas saber, mediante la cual se analizó el desempeño de los estudiantes de los grados tercero y quinto en las pruebas saber de ciencias naturales, identificándose las deficiencias en las competencias de indagación y explicación de fenómenos.

Diario de campo: En el cual se sistematizaron las prácticas investigativas en el aula centradas en la aplicación de las unidades en el marco de la enseñanza para la comprensión dise- 
ñadas para fortalecer las competencias de indagación y explicación de fenómenos. El registro permanente evidenció que es posible mejorar las prácticas, enriquecerlas y transformarlas. Este instrumento permitió hacer un rastreo constante de lo observado en la intervención pedagógica. Adicionalmente, para analizar la aplicación de las rutinas de pensamiento y las unidades en el marco de la enseñanza para la comprensión, se hizo a través de una rejilla, en la cual se relacionaba la rutina, la descripción de la ejecución y los hallazgos. Igualmente, se utilizó fotografía y los videos, con el propósito de brindar información gráfica pertinente para evidenciar algunos procesos de intervención llevados a cabo en la investigación.

Entrevistas y cuestionarios: Se tuvieron en cuenta para obtener la percepción de los estudiantes acerca del proceso de intervención. Mediante preguntas dirigidas se pudo conocer datos sobre actitudes, intereses, opiniones, conocimientos, comportamientos. Se diseñó un formato de cuestionario y para los análisis respectivos se utilizó una rejilla en la cual se relacionó la categoría, los criterios y los hallazgos. Todo esto permitió evidenciar las transformaciones ocurridas en las prácticas de aula destinadas al desarrollo de las competencias de indagación y explicación de fenómenos.

\section{Resultados}

A continuación, se presentan los resultados de la investigación, teniendo en cuenta los objetivos específicos planteados en el estudio y en correspondencia con las etapas declaradas en la metodología:

Diagnóstico del desempeño inicial de estudiantes y de las prácticas pedagógicas de los docentes en el desarrollo de las competencias de indagación y explicación de fenómenos

A continuación, se presentan los hallazgos del diagnóstico realizado, en cuanto al desempeño inicial de los estudiantes frente al desempeño en las pruebas saber, en lo relacionado con las competencias de indagación y explicación de fenómenos en el área de ciencias naturales de los estudiantes de grado tercero y quinto de educación básica primaria. Luego se expone la caracterización inicial de las prácticas pedagógicas de las docentes investigadoras:

\section{- Caracterización del nivel de las competencias de indagación y explicación de fenómenos}

Al observar los desempeños de los estudiantes en las diferentes áreas, aunque demuestran interés por el estudio, dejan evidenciar en sus procesos de aprendizaje pocos resultados en el nivel superior y bajos niveles en el desarrollo de las competencias de argumentación e interpretación. Esto genera en las docentes de los grados primero y quinto de la Institución Educativa Departamental Ricardo González, pertenecientes a la sede rural Canica Baja y sede Urbana, la necesidad de implementar estrategias encaminadas a potenciar los aprendizajes de los estudiantes y mejorar los procesos de enseñanza de los profesores.

Este aspecto, se evidencia en el trabajo de aula, donde algunos estudiantes presentan dificultad para explicar las ideas, sustentar proposiciones, argumentar puntos de vista, establecer comparaciones, extraer conclusiones de lecturas, dar solución a situaciones problémicas, capacidad de formular hipótesis y dar respuestas en diversos ejercicios planteados. De igual forma, se sustenta esta idea con el diálogo pedagógico suscitado entre docentes y 
las descripciones abordadas en las actas de reuniones de área, reuniones de directores de grado, consejos académicos, comisiones de evaluación y promoción de cada periodo.

Las Pruebas Saber para los estudiantes de la educación básica primaria "son aplicadas en Colombia por el Instituto Colombiano para la Evaluación Superior (ICFES): para los grados $3^{\circ}$ y $5^{\circ}$ en las áreas de Matemáticas y Lengua Castellana, y solo para grado $5^{\circ}$ en el área de Ciencias Naturales" (Ortiz-Tobón y García-Rentería, 2019, p. 151). En cuanto al análisis de los resultados de las pruebas Saber de la institución donde se desarrolló el estudio, la competencia de explicación arroja las siguientes interpretaciones: en lo referido a la explicación de fenómenos en los años 2009 y 2014 para el grado quinto $\left(5^{\circ}\right)$ el desempeño alcanzado por los estudiantes fue mínimo con respecto a otras instituciones del departamento y en el 2012 sus resultados fueron débiles.

En la competencia de indagación se evidenció en el año 2009 un desempeño mínimo, en el 2012 un nivel fuerte y en 2014 fueron similares a los de otras instituciones. Se tomaron como referencia los años 2009, 2012 y 2014 debido a que en estos años se aplicaron las pruebas de ciencias naturales. En el año 2016 fue aplicada nuevamente, sin embargo, el acceso a los resultados se obtuvo hasta el año 2017 y la investigación se inició desde el año 2016.

De igual forma, estos bajos niveles de explicación de fenómenos e indagación se evidencian en los resultados de las diferentes evaluaciones realizadas en las aulas y en la aplicación de las pruebas estandarizadas, las cuales generan en la institución educativa la preocupación y la necesidad de plantear estrategias para favorecer dichos procesos, toda vez que son esenciales para el adecuado desarrollo del ser humano en diferentes aspectos.

Debido al arduo trabajo que desarrolla la institución para alcanzar la calidad de la educación frente a todos los procesos de enseñanza y aprendizaje, se hace notoria la necesidad de establecer planes y programas para favorecer cada día más estos procesos, necesarios no sólo para mejorar los resultados en dichas pruebas sino para formar ciudadanos más competitivos y críticos en aspectos relacionados con la explicación de fenómenos e indagación en el proceso de enseñanza de las diferentes áreas del conocimiento.

Con la información obtenida del respectivo análisis, los resultados de las pruebas Icfes de los años 2009, 2012 y 2014 para el grado $5^{\circ}$ se demuestran, en el componente de entorno vivo, la similitud con otras instituciones en los años 2009 y 2014, mientras en el año 2012 fue débil. Por su parte, el componente entorno físico, el desempeño alcanzado fue débil en los años 2009 y 2012, mientras que en los años 2014 fue fuerte, y en el componente de ciencia y tecnología denota que en el 2009 los resultados se ubicaron en nivel fuerte y en los años 2012 y 2014 el resultado fue similar a los de otras instituciones.

Respecto a las competencias, se deduce que el conocimiento científico de los resultados en el año 2009 fue fuerte, en el 2012 débil y en el 2014 nuevamente fuerte. En la competencia de explicación de fenómenos se evidencia en los años 2009 y 2014 un desempeño similar a otras instituciones y en el 2012 estuvo débil en sus resultados, además en la competencia de indagación, en los 3 años mencionados los resultados estaban en nivel mínimo.

Con respecto a las competencias se aprecia en el conocimiento científico un desempeño fuerte en los años 2009 y 2012 y en el año 2014 se mantuvo similar a otras instituciones. Para la competencia de explicación de fenómenos se demuestra que en el año 2009 sus resultados fueron similares a los de otras instituciones, en el año 2012 sus resultados fueron débiles y en el año 2014 subieron a desempeños fuertes. Además, en la competencia de 
indagación para el año 2009 el nivel de desempeño estuvo en mínimo, en el año 2012 en nivel fuerte y en 2014 fueron similares a los de otras instituciones.

Con lo dicho anteriormente, "Podemos inferir que un análisis de un contexto de aula implica el estudio de una gran variedad de aspectos que en conjunto expresarían la complejidad del proceso" (Aragüés, Gil y Gándara, 2014, p. 137). Así las cosas, en la presente investigación, se abordaron aspectos como las implicaciones de las prácticas pedagógicas y la enseñanza para la comprensión en el desarrollo de las competencias de indagación y explicación de fenómenos en estudiantes de primaria.

\section{- Caracterización de las prácticas pedagógicas en la indagación y explicación de fenómenos}

Se tomó como referencia la matriz de evaluación maestro 20/25 que hace parte de la evaluación de carácter diagnóstico formativa. En esta se plantean los desempeños que el docente debe tener para lograr avances significativos en su labor y contribuir al mejoramiento de los aprendizajes. En la Tabla 1, se presenta la reflexión de cada docente participante en lo referido a su práctica de aula:

TABLA 1.

Autoevaluación de la práctica de aula de las docentes investigadoras

\begin{tabular}{|c|c|c|c|c|}
\hline \multicolumn{5}{|c|}{ Criterio: Reflexión y planeación de la práctica educativa y pedagógica } \\
\hline Componente & Aspecto & Docente 1 & Docente 2 & Docente 3 \\
\hline \multirow{3}{*}{$\begin{array}{l}\text { Pertinencia de } \\
\text { los propósitos } \\
\text { pedagógicos y } \\
\text { disciplinares }\end{array}$} & $\begin{array}{l}\text { Establece } \\
\text { propósitos claros } \\
\text { en su práctica } \\
\text { educativa. }\end{array}$ & $\begin{array}{l}\text { Se realizaba una } \\
\text { planeación semanal } \\
\text { con las actividades } \\
\text { para cada día. }\end{array}$ & $\begin{array}{l}\text { Establecía propósitos } \\
\text { sin conocer algunas } \\
\text { características de los } \\
\text { estudiantes. }\end{array}$ & $\begin{array}{l}\text { Se tenía clara la temática } \\
\text { a abordar, pero no se } \\
\text { trazaban los objetivos } \\
\text { específicos de la clase. }\end{array}$ \\
\hline & $\begin{array}{l}\text { Los contenidos se } \\
\text { articulan con el } \\
\text { Plan de Estudios } \\
\text { de la institución } \\
\text { educativa. }\end{array}$ & $\begin{array}{l}\text { Se utilizaba el } \\
\text { plan de estudios } \\
\text { de la institución y } \\
\text { se articulaba con } \\
\text { el desarrollo de la } \\
\text { práctica educativa. }\end{array}$ & $\begin{array}{l}\text { Tenía en cuenta el } \\
\text { plan de estudios en } \\
\text { la organización de la } \\
\text { planeación y participe } \\
\text { activamente en las } \\
\text { modificaciones al iniciar } \\
\text { el año escolar. }\end{array}$ & $\begin{array}{l}\text { Las temáticas que se } \\
\text { abordaban tenían como } \\
\text { referente los estándares y } \\
\text { el plan de esvtudios de la } \\
\text { Institución Educativa. }\end{array}$ \\
\hline & $\begin{array}{l}\text { Organiza el } \\
\text { conocimiento } \\
\text { disciplinar a partir } \\
\text { del nivel de sus } \\
\text { estudiantes. }\end{array}$ & $\begin{array}{l}\text { Organizaba el } \\
\text { conocimiento } \\
\text { disciplinar de } \\
\text { acuerdo con los } \\
\text { contenidos. }\end{array}$ & $\begin{array}{l}\text { El conocimiento } \\
\text { disciplinar se organizó } \\
\text { sin tener en cuenta los } \\
\text { conocimientos previos } \\
\text { de los estudiantes ni sus } \\
\text { características. }\end{array}$ & $\begin{array}{l}\text { En lo posible, se tenían } \\
\text { en cuenta los procesos } \\
\text { de desarrollo de los } \\
\text { estudiantes. Sin embargo, } \\
\text { no se hacía seguimiento a } \\
\text { este aspecto. }\end{array}$ \\
\hline \multirow[t]{2}{*}{$\begin{array}{l}\text { Propuesta } \\
\text { pedagógica y } \\
\text { disciplinar (1) }\end{array}$} & $\begin{array}{l}\text { Reflexiona sobre su } \\
\text { práctica educativa y } \\
\text { pedagógica. }\end{array}$ & $\begin{array}{l}\text { Se capacitaba para } \\
\text { adquirir nuevos } \\
\text { conocimientos y } \\
\text { aplicarlos en su } \\
\text { aula. }\end{array}$ & $\begin{array}{l}\text { Se hizo uso de la } \\
\text { experiencia para } \\
\text { analizar, sustentar } \\
\text { y proponer cambios o } \\
\text { transformaciones, pero } \\
\text { muy pocas ocasiones } \\
\text { recurrí al dialogo } \\
\text { pedagógico. }\end{array}$ & $\begin{array}{l}\text { Posterior a la realización } \\
\text { de las actividades, se } \\
\text { reflexionaba sobre la } \\
\text { práctica a partir del } \\
\text { interés de los niños } \\
\text { en las actividades, sus } \\
\text { desempeños y si se cumplía } \\
\text { o no con el objetivo. }\end{array}$ \\
\hline & $\begin{array}{l}\text { Demuestra dominio } \\
\text { pedagógico y } \\
\text { disciplinar. }\end{array}$ & $\begin{array}{l}\text { Preparaba sus } \\
\text { clases para que } \\
\text { los estudiantes } \\
\text { comprendieran los } \\
\text { temas. }\end{array}$ & $\begin{array}{l}\text { Se utilizaron estrategias } \\
\text { de enseñanza acorde a la } \\
\text { disciplina que enseño. }\end{array}$ & $\begin{array}{l}\text { Se contaba con el dominio } \\
\text { pedagógico y disciplinar, } \\
\text { de igual forma, con } \\
\text { anterioridad se preparaba } \\
\text { la temática a trabajar. }\end{array}$ \\
\hline
\end{tabular}




\begin{tabular}{|c|c|c|c|c|}
\hline \multicolumn{5}{|c|}{ Criterio: Praxis pedagógica } \\
\hline Componente & Aspecto & Docente 1 & Docente 2 & Docente 3 \\
\hline \multirow[t]{2}{*}{$\begin{array}{l}\text { Propuesta } \\
\text { pedagógica y } \\
\text { disciplinar (2) }\end{array}$} & $\begin{array}{l}\text { Hay una } \\
\text { comunicación } \\
\text { permanente y } \\
\text { adecuada entre } \\
\text { el docente y sus } \\
\text { estudiantes. }\end{array}$ & $\begin{array}{l}\text { Se brindaron } \\
\text { espacios de } \\
\text { participación para } \\
\text { que los estudiantes } \\
\text { expresaran sus } \\
\text { saberes. }\end{array}$ & $\begin{array}{l}\text { Las interacciones del } \\
\text { docente durante la clase } \\
\text { generalmente estaban } \\
\text { orientadas al proceso de } \\
\text { enseñanza aprendizaje }\end{array}$ & $\begin{array}{l}\text { Se manejaban canales de } \\
\text { comunicación asertivos } \\
\text { con los estudiantes, donde } \\
\text { se permitía escuchar sus } \\
\text { inquietudes y sugerencias. }\end{array}$ \\
\hline & $\begin{array}{l}\text { Propicia estrategias } \\
\text { de participación } \\
\text { de los estudiantes } \\
\text { que favorecen su } \\
\text { aprendizaje. }\end{array}$ & $\begin{array}{l}\text { Se utilizaban } \\
\text { métodos que } \\
\text { permitieron la } \\
\text { participación de } \\
\text { los estudiantes en } \\
\text { el desarrollo de la } \\
\text { clase. }\end{array}$ & $\begin{array}{l}\text { Utilizaba estrategias } \\
\text { de participación } \\
\text { donde la mayoría de } \\
\text { los estudiantes se } \\
\text { involucraban en los } \\
\text { procesos de aprendizaje. }\end{array}$ & $\begin{array}{l}\text { Constantemente se } \\
\text { generaban espacios } \\
\text { que potencializaban } \\
\text { el aprendizaje de los } \\
\text { estudiantes. }\end{array}$ \\
\hline \multirow[t]{2}{*}{$\begin{array}{l}\text { Interacción } \\
\text { pedagógica }\end{array}$} & $\begin{array}{l}\text { Utiliza estrategias } \\
\text { que generan interés } \\
\text { de los estudiantes } \\
\text { en las actividades } \\
\text { de aula. }\end{array}$ & $\begin{array}{l}\text { Las prácticas de } \\
\text { aula generaban la } \\
\text { participación de los } \\
\text { estudiantes. }\end{array}$ & $\begin{array}{l}\text { Planteaba situaciones } \\
\text { o actividades que } \\
\text { propiciaban que } \\
\text { los estudiantes se } \\
\text { involucraran durante } \\
\text { toda la clase. }\end{array}$ & $\begin{array}{l}\text { Se incorporaban en el } \\
\text { aula actividades que } \\
\text { fueran llamativas a los } \\
\text { estudiantes. }\end{array}$ \\
\hline & $\begin{array}{l}\text { Utiliza estrategias } \\
\text { de evaluación } \\
\text { formativa en } \\
\text { el proceso de } \\
\text { enseñanza y } \\
\text { aprendizaje. }\end{array}$ & $\begin{array}{l}\text { La evaluación era } \\
\text { un proceso con el } \\
\text { cual se verificaban } \\
\text { los aprendizajes. }\end{array}$ & $\begin{array}{l}\text { Utilizaba algunas } \\
\text { estrategias para evaluar } \\
\text { a los estudiantes en el } \\
\text { proceso de enseñanza y } \\
\text { aprendizaje, sin hacer } \\
\text { la retroalimentación } \\
\text { pertinente. }\end{array}$ & $\begin{array}{l}\text { Se realizaba una } \\
\text { evaluación al terminar } \\
\text { cada temática abordada. }\end{array}$ \\
\hline \multirow{2}{*}{$\begin{array}{l}\text { Procesos } \\
\text { didácticos }\end{array}$} & $\begin{array}{l}\text { Utiliza estrategias } \\
\text { metodológicas y } \\
\text { recursos educativos. }\end{array}$ & $\begin{array}{l}\text { Se utilizaban } \\
\text { metodologías que } \\
\text { favorecían los } \\
\text { aprendizajes de los } \\
\text { estudiantes con } \\
\text { recursos propios. }\end{array}$ & $\begin{array}{l}\text { Las estrategias } \\
\text { utilizadas durante el } \\
\text { desarrollo de las clases } \\
\text { fueron monótonas y } \\
\text { tradicionalistas. }\end{array}$ & $\begin{array}{l}\text { Constantemente se } \\
\text { empleaban recursos } \\
\text { educativos que reforzaban } \\
\text { las temáticas abordadas. }\end{array}$ \\
\hline & $\begin{array}{l}\text { Reconoce las } \\
\text { características de } \\
\text { sus estudiantes. }\end{array}$ & $\begin{array}{l}\text { Los estudiantes } \\
\text { expresaban sus } \\
\text { sentimientos y } \\
\text { emociones a través } \\
\text { de la participación } \\
\text { en las clases. }\end{array}$ & $\begin{array}{l}\text { Se tuvieron en cuenta las } \\
\text { características sociales, } \\
\text { económicas o culturales } \\
\text { de los estudiantes en el } \\
\text { desarrollo de la práctica } \\
\text { educativa y pedagógica. }\end{array}$ & $\begin{array}{l}\text { Las actividades y las } \\
\text { temáticas que se abordaban } \\
\text { se planeaban de acuerdo } \\
\text { con las particularidades de } \\
\text { los estudiantes. }\end{array}$ \\
\hline
\end{tabular}

Fuente: Elaboración propia.

Al observar la metodología para el abordaje de las clases, se detecta en los docentes de la institución un manejo de corte tradicionalista, cuyas prácticas pedagógicas en algunos casos son obsoletas, poco innovadoras, con didácticas rutinarias, renuentes al cambio y a nuevas dinámicas de aprendizaje, escasas en la experimentación y en la búsqueda de conocimientos y exiguo desarrollo del pensamiento. El proceso de aprendizaje enfatizaba más en conocimientos propios de cada disciplina que en el desarrollo de habilidades donde se priorice el aprendizaje significativo. Estos aspectos distaban totalmente del modelo pedagógico constructivista en el cual se apoya el Proyecto Educativo Institucional de la Institución Educativa Departamental Ricardo González. Esta situación había afectado el 
desempeño de los estudiantes en pruebas externas, en la media en "que las pruebas saber indican en gran parte la calidad de los procesos de enseñanza aprendizaje en cada una de las instituciones del país, puesto que los resultados están enfocados en la evaluación por competencias" (Velásquez, Celis y Hernández, 2017, p. 35).

Lo anterior significa que, para el desarrollo de las competencias de indagación y explicación de fenómenos, cobra importancia, las estrategias empleadas por el docente para brindar a los estudiantes la posibilidad de convertir sus inquietudes en preguntas provocadoras que "lleve a la indagación, a la búsqueda de información, permitiendo establecer hipótesis y proyecciones, y así trabajar con fuentes primarias y secundarias y que establezcan nuevas conexiones y nuevas relaciones" (Narváez, 2014, p. 18). En este sentido, debido a la problemática identificada, con la investigación se implementaron estrategias apropiadas para el fortalecimiento de las competencias de indagación y explicación de fenómenos que mejoraron los procesos de pensamiento de los estudiantes, desde el marco de la enseñanza para la comprensión, como se evidencia en los siguientes apartados.

Intervención para el fortalecimiento de la indagación y la explicación de fenómenos a través del marco de la enseñanza para la comprensión

Se transformaron las planeaciones y se adoptó un nuevo formato enfocado en el marco de la enseñanza para la comprensión "con el fin de que esta 'planeación', tomara un rumbo más centrado, más claro y definido hacia lo que realmente vale la pena que los estudiantes comprendan" (Villamizar et al., 2019, p. 40), logrando que la enseñanza y el aprendizaje vincularan desempeños significativos para los estudiantes, al tener en cuenta el contexto y lo interdisciplinar con las necesidades de los estudiantes junto a un clima de aula propicio que posibilitó la participación y permitió a los docentes cuestionarse acerca de su quehacer pedagógico para estar actualizado con el conocimiento didáctico del contenido e innovando en el aula.

Así mismo, mediante las planeaciones fue posible programar actividades que exigían ir más allá de la información dada y optimizar el uso del tiempo para que los aprendizajes fueran más fructíferos, la utilización de los tópicos generativos al ser abarcadores motivaron a los estudiantes, suscitaron la curiosidad, aportaron ideas que los condujeron a establecer relaciones, a cumplir con la programación planteada, involucrándose directamente en el trabajo de aula y manejando una buena comunicación entre docente y estudiantes. Esto permitió fortalecer la enseñanza a partir de la interacción con los demás.

Las unidades en el marco de la enseñanza para la comprensión se plantearon de acuerdo con los estándares curriculares y los Derechos Básicos de Aprendizaje del Ministerio Nacional de Colombia, determinados para el grado primero y quinto, ejecutadas tanto en la sede B como en la sede rural Canica Baja, donde las docentes fueron autónomas y adaptaron algunas estrategias de acuerdo con las necesidades de su grupo. En la Tabla 2 se relaciona la descripción de la ejecución de las unidades en el marco de la enseñanza para la comprensión: 
TABLA 2.

Síntesis de las unidades implementadas

\begin{tabular}{clcc}
\hline & Ejecución de unidades en el marco de enseñanza para la comprensión \\
\hline Tópicos & Docente 1 & Docente 2 & Docente 3 \\
\hline
\end{tabular}

Se inició la clase a partir de los saberes previos de los estudiantes, con preguntas que cautivaron el interés por aprender y conocer más de los sentidos a través de

Con mis sentidos exploro, descubro, conozco y le doy significado a los estímulos de mi entorno la rutina de pensamiento: conversación sobre el papel; luego por medio de una lluvia de ideas cada uno expresó sus comprensiones, después elaboraron un mapa mental apoyados en imágenes y se socializaron. En este momento de la actividad los aportes de los estudiantes fueron significativos ya que se compartieron experiencias enriquecedoras con los saberes adquiridos durante la clase.
Se inició con una práctica de sensibilización donde los estudiantes entraron en contacto con una serie de estímulos para explicar sus características y la forma de percibirlos, posteriormente se aplicó la rutina "conversación sobre papel" con el fin de construir y poner al descubierto niveles de comprensión de una forma colaborativa al exponer ideas. La conversación partió de la pregunta ¿cuál de los sentidos es menos importante y por qué?

Se hizo una lluvia de ideas y participaron en la construcción de un mapa mental. Se socializó el video sobre los sentidos y las características de estos para complementar el mapa mental.
Se inició con la rutina de pensamiento "conversación sobre papel" a fin de construir comprensiones de una forma colaborativa al exponer ideas, cuestionar a otros y desarrollar comprensiones de mayor profundidad. La conversación partió de la pregunta ¿Cuál de los sentidos es menos importante y por qué? Cada uno escribió su percepción, la pegaron en el tablero dando lugar a ser leídas y visualizadas por otros compañeros. Seguido a esto, se llevó a cabo la construcción de un mapa mental apoyados en imágenes. Se proyectó un video y se realizó la respectiva socialización.

Realizaron una presentación en PowerPoint sobre los sentidos. Como proyecto final de síntesis elaboraron una cartelera donde se especificaban los cuidados a tener con cada sentido.
Se inició a la clase con un recorrido guiado por las zonas verdes de la institución, durante el recorrido se les pidió a los estudiantes que detallaran cada planta según el tamaño color, forma...luego en el aula se hizo un conversatorio y se complementó la actividad con la rutina de pensamiento: veo, pienso,

Las plantas son vida y me brindan lo necesario para vivir me pregunto. La docente mostró una imagen del proceso de germinación de una planta, indagó para estar segura de que todos los estudiantes habían visto alguna vez este proceso, al obtener una respuesta afirmativa les invitó a pensar en cada planta y hacer preguntas comparativas referentes al tamaño de las plantas, de las hojas, del tallo de la forma como se da el fruto, del color, entre otras. Todos los niños participaron activamente.
Se presentó el tópico generativo, el hilo conductor y las metas de comprensión. Luego realizaron la Rutina de pensamiento "Conversar con el papel", dando respuesta a las preguntas ¿Qué es un Ecosistema? y ¿Qué ecosistemas conoces? ¿Cuáles hay en Subachoque? Los estudiantes pegaron y compartieron sus respuestas. Se hizo una presentación con diapositivas relacionadas con los ecosistemas. A medida que se presentaban las diapositivas, por medio de preguntas se generó la participación de los estudiantes. También se entregaron unas palabras a los estudiantes, cada uno las leyó, procedieron a organizar entre todos un mapa conceptual en el tablero. Así mismo se pidió que observaran el mapa y con relación a este hicieran una invitación a cuidar los diferentes ecosistemas y ayudar a la preservación de las especies.
Se hizo una caminata por los alrededores de la escuela para observar las plantas que allí se encontraban, posteriormente se llevó a cabo la rutina "veo-pienso-me pregunto", donde los estudiantes expresaron que vieron. Posteriormente se les preguntó ¿Por qué son importantes las plantas? Seguido a esto elaboraron el dibujo de una planta para ubicar sus partes, se visualizó un video para detallar la función de cada una de sus partes, se realizó una actividad de germinación donde cada estudiante debía colocar una semilla en un vaso transparente con agua y algodón y registrar los cambios ocurridos en la semilla cada día. Como proyecto final de síntesis se investigaron los diferentes cultivos de la región, su tiempo de siembra, de cosecha y las características de las plantas y frutos y se elaboró un álbum. Se elaboró una manualidad denominada cabeza de césped, con alpiste, aserrín, medias veladas, y ojitos, con el paso del tiempo y al regarlo periódicamente generaría pasto, el cual se debía cortar y cuidar para no generar hongos. 


\begin{tabular}{|c|c|c|c|}
\hline \multicolumn{4}{|c|}{ Ejecución de unidades en el marco de enseñanza para la comprensión } \\
\hline Tópicos & Docente 1 & Docente 2 & Docente 3 \\
\hline $\begin{array}{l}\text { Descubriendo } \\
\text { el mundo } \\
\text { animal }\end{array}$ & $\begin{array}{l}\text { Se explicó a los estudiantes } \\
\text { que es el hábitat, a través } \\
\text { de la rutina de pensamiento } \\
\text { ¿Qué te hace decir eso? Cada } \\
\text { uno expresó su saber sobre } \\
\text { el tema, y se generaron más } \\
\text { cuestionamientos a través de la } \\
\text { participación masiva del grupo. } \\
\text { Se realizó la observación de } \\
\text { unas imágenes de un hábitat } \\
\text { terrestre, hábitat aéreo y un } \\
\text { hábitat acuático para que } \\
\text { los estudiantes pensaran y } \\
\text { aportaran ideas acerca de } \\
\text { lo observado, luego a cada } \\
\text { estudiante se le entregó } \\
\text { imágenes de animales para que } \\
\text { seleccionaran el hábitat de cada } \\
\text { animal, de acuerdo con algunas } \\
\text { características orientadas por } \\
\text { la docente para poder ubicarlos, } \\
\text { los hábitats estaban pegados } \\
\text { en el salón de clase. Por último, } \\
\text { elaboraron su animal favorito } \\
\text { en plastilina. }\end{array}$ & $\begin{array}{l}\text { Se hizo la presentación del tópico } \\
\text { generativo y las metas para que los } \\
\text { estudiantes iniciaran la exploración, } \\
\text { discutieron sobre la pregunta de } \\
\text { investigación ¿Cuáles son las partes } \\
\text { que conforman el sistema reproductor } \\
\text { masculino y qué función cumplen? } \\
\text { Se proyectó el video sobre las partes } \\
\text { del aparato reproductor masculino y su } \\
\text { función para posteriormente ubicar en } \\
\text { una imagen dada las partes de este y } \\
\text { después aplicar la rutina veo pienso y me } \\
\text { pregunto dónde se pretendió conseguir } \\
\text { que los estudiantes mostraran sus } \\
\text { aprendizajes y dominio de vocabulario. } \\
\text { Se organizó trabajo colaborativo en } \\
\text { pares, cada miembro expresó sus ideas } \\
\text { y conceptos sobre las funciones de } \\
\text { cada parte del sistema reproductor y } \\
\text { entre todos las plasmaron en un mapa } \\
\text { conceptual. Finalmente, los estudiantes } \\
\text { elaboraron un friso sobre los hábitos } \\
\text { de higiene y cuidados del sistema } \\
\text { reproductor masculino. }\end{array}$ & $\begin{array}{l}\text { Se inició con la pregunta ¿En qué lugar } \\
\text { viven los animales? a lo cual los estudiantes } \\
\text { respondieron: (en el agua, en la tierra, en el } \\
\text { cielo, en las fincas, en las casas) al empelar la } \\
\text { rutina ¿Qué te hace decir eso?, los estudiantes } \\
\text { respondieron: por que viven en la finca del } \\
\text { patrón, mi mascota vive en mi casa, porque } \\
\text { algunos pueden vivir en el agua, en el aire y en } \\
\text { la tierra; porque tienen alas, aletas y patas. } \\
\text { Posteriormente se hizo la observación de } \\
\text { imágenes de un hábitat terrestre, un hábitat } \\
\text { acuático y aéreo presentados en papel Kraft } \\
\text { alrededor del salón donde los estudiantes } \\
\text { pensaron y se cuestionaron acerca de lo que } \\
\text { están mirando. Posteriormente se les hizo } \\
\text { entrega de varios recortes de animales con } \\
\text { diferentes características, los colorearon y los } \\
\text { pegaron en el hábitat correspondiente según } \\
\text { sus características, así mismo explicaron el } \\
\text { porqué de su clasificación. Seguido a esto } \\
\text { los estudiantes elaboraron en plastilina su } \\
\text { animal favorito y en casa indagaron sobre sus } \\
\text { características, con la información recolectada } \\
\text { elaboraron un cuento. }\end{array}$ \\
\hline
\end{tabular}

Se pidió con anticipación a los estudiantes indagar y preparar algún experimento para poderlo exponer ante sus compañeros y explicar paso a paso el proceso que llevó a cabo para que su invento funcionará.

Se inició con una lectura de introducción titulada "el sueño de John" y mediante una ronda de preguntas sobre la misma se hizo la socialización.

También se aprovechó para hacer la indagación sobre los conocimientos previos que traen los niños acerca de los experimentos. Posteriormente se procedió a que los niños hicieran su exposición y se tuvo en cuenta la participación de los estudiantes la capacidad para explicar y sustentar frente a sus compañeros. Se utilizó por primera vez la rutina de pensamiento color símbolo imagen, donde los niños pudieron evidenciar sus aprendizajes, su pensamiento, por ejemplo Henry, el color que tomó para su rutina fue el color azul dice "El color azul es la creatividad, además es mi color favorito me motiva a seguir adelante no rendirme y ser feliz con lo que quiero, me propongo día a día" su dibujo fue una pica donde a un lado del pico le escribió esfuerzo; El pico demuestra el poder y el esfuerzo en que se apoyan los valores utilizados en los proyectos del día a día y la imagen es un niño con un corazón en la mano y en la otra una pica.
Se inició con la lectura "La historia de Jhon", basada en el genio que invento el televisor, los estudiantes expresaron sus ideas frente a la lectura. El estudiante Mauricio pregunta: ¿El niño tenía mucha plata para crear eso? a lo que sus compañeros respondieron que cualquier persona lo podría hacer; que siempre se deben lograr los sueños, que hay personas que tienen mucha inteligencia que pueden crear cosas, posteriormente se le preguntó a los estudiantes acerca de lo que creían que era un experimento a lo cual respondieron: es crear algo nuevo, inventar una cosa con diferentes materiales, descubrir cómo funciona algo. Seguido a esto se inició la exposición de experimentos que con anticipación cada estudiante indagó y preparó para presentar frente a todo el curso con los materiales propuestos y el objetivo a conseguir por medio de la manipulación de los elementos, atrayendo la atención de sus compañeros por las cosas novedosas que se presentaron.

Al finalizar la sesión se llevó a cabo la rutina de pensamiento "color-símbolo-imagen". La mayoría de los colores fueron el amarillo y blanco, al preguntarles por qué lo eligieron el estudiante Camilo respondió: porque las batas de los científicos son blancas, Teresa se inclinó por el amarrillo porque para ella eran ideas que se iluminaban como un bombillo. Algunos símbolos fueron gafas, microscopios e imágenes de los experimentos, lo cual se evidenció que para ellos el símbolo y la imagen eran prácticamente lo mismo.

Fuente: Elaboración propia. 
Después de hacer un análisis de lo ejecutado en las unidades de enseñanza para la comprensión, se encontraron como puntos de convergencia que todas las docentes involucraron las rutinas del pensamiento en la clase ya que hacen más interesante el trabajo. Por otro lado, se motivó a los estudiantes hacia el trabajo colaborativo con el fin de fortalecer los aprendizajes y la expresión de saberes a través de lluvia de ideas. Se evidenció una participación espontánea que demostró el dominio de los estudiantes por cada uno de los tópicos abordados. Además, se despertó el interés por indagar y explicar, los estudiantes se apropiaron de un vocabulario más específico del área e hicieron visible su pensamiento. Durante el desarrollo de las actividades se hizo una constante retroalimentación con un seguimiento a sus aprendizajes y el desarrollo de sus conocimientos.

Un aspecto que se opuso al desarrollo total de las unidades fue el manejo del tiempo, debido a que, por la alta participación de los estudiantes en los desempeños de comprensión, era necesario contar con horas adicionales de clase. Todas las docentes no manejaron el mismo tópico generativo a pesar de haber realizado una planeación en conjunto. Se observa que al momento de la aplicación y de la ejecución de las unidades de enseñanza para la comprensión en el aula se respetó la autonomía de cada una y a pesar de ser las mismas actividades, se desarrollaron de forma diferente llegando a cumplir el mismo objetivo por vías distintas. De esta manera la EpC, como lo plantea Chaves y Barrios (2017), ofrece una oportunidad de diseño para el trabajo en las aulas a través de un modelo de planificación, una lógica de concepción próxima a la enseñanza, el aprendizaje y la ética, en la cual se concibe que todos somos capaces de comprender y construir el conocimiento.

Validación de las transformaciones de las prácticas pedagógicas desde la perspectiva de los estudiantes

Para contrastar las percepciones de los estudiantes con relación a las prácticas de aula desarrolladas por las docentes antes y después de la ejecución del proyecto de investigación, se les proporcionó a los estudiantes una serie de preguntas orientadas a valorar las transformaciones en lo referido a la enseñanza, el aprendizaje y el desarrollo del pensamiento.

Al realizar la respectiva sistematización se hizo notorio como los estudiantes evidenciaron una transformación en las prácticas de aula de sus docentes, toda vez que estas "son situadas; son llevadas adelante por un educador singular, en aulas... reales, con estudiantes particulares que van a aprender un contenido específico con las estrategias didácticas por las que ha optado y está implementando ese profesor" (Ferreyra y Rúa, 2018, p. 153). Así las cosas, antes de la puesta en marcha del proyecto, las clases eran de corte tradicional, con poca participación de los estudiantes donde la docente explicaba y ellos se limitaban a seguir las indicaciones dadas sin dar espacio de participación en el proceso de aprendizaje. Posterior a la implementación del proyecto, las clases se mostraron más agradables y divertidas por las diversas actividades en las cuales los estudiantes eran los agentes activos de 
su propio proceso, se emplearon diferentes herramientas didácticas y tecnológicas, las cuales ayudaron a desarrollar una mejor comprensión.

Los estudiantes manifestaron que el trabajo en equipo fue muy importante porque cada uno cumplió con un rol que le hacía sentirse importante dentro del grupo. Se fortalecieron valores como el respeto por las opiniones del otro, la seguridad para expresarse de forma espontánea dando a conocer sus conocimientos. Ayudó a profundizar, socializar las ideas y exponer los puntos de vista propios, les permitió aclarar dudas y apoyar el proceso de aprendizaje de los compañeros, aunque la mayoría coincidieron en lo valioso e importante del trabajo en equipo; algunos de los cursos partícipes de la sede B manifestaron disgusto por los niveles de ruido, porque no se respetaban los turnos para opinar, no escuchaban a los demás y les costaba llegar a acuerdos grupales.

En cuanto a cómo les gustaría las clases de ciencias naturales, coincidieron en que las deseaban prácticas, didácticas, con juegos, experimentos en lo posible fuera del salón, donde se pueda tener contacto con el entorno, sea un aprendizaje más vivencial, se promueva la investigación de los temas de interés y se empleen elementos científicos como el uso del microscopio. Los estudiantes manifestaron la intención de expresar sus aprendizajes con el diálogo, la participación en clase, la socialización de sus tareas y sustentación de ideas mediante el trabajo en equipo. Les gustaría el uso frecuente de ayudas tecnológicas y de videos educativos, así como las actividades relacionadas con el desarrollo de la imaginación y la investigación. En este mismo sentido, manifestaron que hacer visible el pensamiento es demostrar a los demás sus aprendizajes y apropiaciones de manera espontánea, dar opiniones, compartir lo investigado en casa, expresar lo aprendido a través de carteleras y exposiciones y explicar lo enseñado por las profesoras a compañeros y familiares.

Al consultar cuál unidad les llamó la atención, los estudiantes escogieron la de “Genios en acción” por ser la más llamativa al utilizar la investigación como recurso de aprendizaje, no fue necesario escribir y todos participaron con un experimento, lo cual exigió pensar, aprender y valorar el esfuerzo y el trabajo de los compañeros, resaltando el valor de la responsabilidad. Los estudiantes resaltaron la labor de los padres, quienes les colaboraron con sus tareas, explicándoles y ayudándoles a resolverlas, apoyados en internet, enciclopedias, libros y sus conocimientos propios. No obstante, una minoría no recibió acompañamiento en casa.

En cuanto a la expresión de sus ideas, los estudiantes destacaron la participaron en clase con diálogos entre compañeros, al dar las opiniones acerca de las temáticas, desarrollaron la capacidad de pedir la palabra para su intervención y expresaron con seguridad aquello que pensaban y resolvieron las inquietudes con suficientes fundamentos. Además, valoraron el respeto por las ideas, al recibir realimentación de las opiniones con una actitud fraterna y con la intención de corregir y promover el aprendizaje en la otra persona.

En lo referido al uso de rutinas de pensamiento en el aula, los estudiantes manifestaron su interés por este tipo de herramientas, porque ayudan a expresar ideas, los invitan a pensar, comprenden mejor los temas y comparten con sus compañeros sus conocimientos, son divertidas, ayudan a desarrollar el pensamiento, mejoran 
la memoria, desarrollan el pensamiento y dan libertad de expresar lo más importante. En esta perspectiva, Chiliquinga y Balladares (2020) conciben las rutinas de pensamiento como una creación apremiante de aplicar, toda vez que promueve el pensamiento crítico y creativo transformando de esta manera los procedimientos tradicionales de la enseñanza.

Al preguntar sobre la comprensión de la competencia "indagar", la definieron como consultar, investigar, averiguar sobre los temas trabajados en clase y la manera en que aprenden al leer y consultar sobre un tópico en especial, así mismo lo relacionan con buscar información en libros o preguntar a personas expertas en los temas. Con respecto a la definición de la competencia de explicación, la relacionan con decir las cosas de forma clara, aportar ideas, dar a conocer aquello que se piensa y dar opiniones frente a los demás con respecto a un contenido abordado en la clase. Estas dos competencias se fortalecieron debido al interés despertado en los estudiantes, los tópicos generativos y la aparición de preguntas provocadoras en el desarrollo de las unidades en el marco de la enseñanza para la comprensión, facilitándose el aprendizaje de los estudiantes y mejorando las estrategias didácticas en el aula de las profesoras investigadoras.

\section{Conclusiones}

De acuerdo con los resultados obtenidos y en concordancia con los objetivos propuestos se concluye que:

El análisis de las pruebas saber sirvió como punto de partida para detallar las falencias que presentaban los estudiantes en cuanto a las competencias científicas evaluadas por el Icfes, específicamente en la indagación y la explicación de fenómenos, las cuales se encontraban en un nivel mínimo. Además, en las pruebas institucionales, la forma de evaluar se regía por preguntas que se limitaban al aspecto literal, sin un proceso de análisis y reflexión.

El fortalecimiento de las competencias de indagación y explicación de fenómenos específicas del área de ciencias naturales, son esenciales para que los estudiantes logren construir un pensamiento científico, basados en la observación, la formulación de interrogantes, la resolución de problemas, la construcción de argumentos, el sustento de ideas, la creación de hipótesis y predicciones. De igual forma, la búsqueda de información en diferentes fuentes de consulta, la interpretación y la organización, apoyaron la construcción de nuevos saberes y generaron en el estudiante una actitud crítica y analítica para dar razón sobre el porqué de un fenómeno, llevándolo a hacer visible su pensamiento a través de escritos, exposiciones, gráficas, dibujos y experimentos que les permitieron dar explicaciones sobre el mundo natural.

El marco de la enseñanza para la comprensión permitió las transformaciones de las prácticas de aula al brindar la posibilidad a las docentes investigadoras de programar el desarrollo de sus clases de una manera más abarcadora, por medio de tópicos generativos cautivadores de la atención de los estudiantes, invitándolos a indagar e ir más allá de lo abordado en clase, incentivándolos a consultar diferentes 
fuentes como textos, enciclopedias, revistas y recursos tecnológicos con el fin de profundizar y dar a conocer sus aprendizajes por medio de explicaciones frente a sus compañeros.

Las unidades del marco de la enseñanza para la comprensión diseñadas y aplicadas contribuyeron a planificar los procesos de enseñanza y de aprendizaje de acuerdo con el desarrollo de competencias, desligándose del trabajo por contenidos, con el cual se acostumbraba a desarrollar las clases, dando paso al trabajo con actividades significativas que complementaron los saberes previos de los estudiantes con sus nuevos conocimientos. Las metas de comprensión planteadas en cada unidad brindaron claridad tanto al docente como al estudiante sobre las comprensiones específicas que se pretendían desarrollar en la disciplina a trabajar, al tener en cuenta la dimensión de contenido, método, propósito y de comunicación. Los desempeños de comprensión dieron paso a la organización de acciones, a fin de hacer visible su pensamiento y desarrollar su comprensión, al tener la necesidad de ir más allá de lo que sabían y hacer uso de ideas y preguntas para desarrollar nuevos conocimientos basados en tres momentos claves como lo son la exploración del tópico, la investigación guiada y el proyecto final de síntesis.

Dentro de este proceso de investigación no sólo los estudiantes experimentaron las transformaciones en las clases, de la misma forma las docentes lograron adquirir nuevos conocimientos para dar un giro relevante a sus prácticas, como parte de esto se abrió paso al diálogo entre pares el cual generó la oportunidad de socializar varias experiencias que contribuyeron a fortalecer las dinámicas de aula y el diseño de planeaciones. Las docentes investigadoras a partir de su propia autorreflexión vieron la necesidad de evaluar el antes, el después y el ahora de sus prácticas de aula con el fin de modificar e innovar los procesos de enseñanza y de aprendizaje, creando escenarios propicios y acordes al contexto donde se desenvuelven los estudiantes y las familias para generar un alto impacto en cuanto a los niveles académicos y el desarrollo humanos de los niños, niñas y jóvenes.

En este sentido, ahora la labor práctica del aula está mediada por la actividad de los estudiantes quienes se caracterizan por la curiosidad y el deseo de aprender, lo cual debe ser usado por el maestro, con el fin de profundizar y motivar hacia el aprendizaje científico. Generalmente los niños se cuestionan por los procesos de su entorno. Al abordarlos como objeto de estudio se está favoreciendo el conocimiento del medio ambiente y de esta manera se ayuda a tomar conciencia de la importancia que tiene en la vida y la necesidad de cuidarlo y protegerlo. 


\section{REFERENCIAS}

Angarita, J. (2018). Apropiación de la realidad aumentada como apoyo a la enseñanza de las ciencias naturales en educación básica primaria. Revista Boletín Redipe, 7(12), 144-157. Recuperado de https://revista.redipe.org/index.php/1/article/view/655_

Aragüés, A., Gil, M. y Gándara, M. (2014). Análisis del papel de los maestros en el desarrollo de actividades de indagación en el practicum de primaria. Didáctica de las ciencias experimentales y sociales, 28, 135-151. https://doi.org/10.7203/dces.28.3523

Ávila, R. (2005). La producción de conocimiento en la investigación acción pedagógica (IAPE): balance de una experimentación. Educa ção e Pesquisa, 31(3), 503-519. Disponible en http://www.educacaoepesquisa.fe.usp.br/?p=775

Blythe, T. (1999). La enseñanza para la comprensión, guia para el docente. Buenos Aires: Paidos.

Burgos, D. y Cifuentes, J. (2015). La práctica pedagógica investigativa: entre saberes, quereres y poderes. Revista Horizontes Pedagógicos 17(2), 118-127. Disponible en https://horizontespedagogicos.ibero.edu.co/article/view/17210

Cifuentes, J. (2019). Aprendizaje del marco de la enseñanza para la comprensión en profesores: un abordaje desde las trayectorias de pensamiento. Revista Virtual Universidad Católica del Norte, (57), 3-23. https://doi.org/10.35575/rvucn.n57a2_

Cifuentes, J. (2015). Enseñanza para la comprensión: opción para mejorar la educación. Revista Educación y Desarrollo Social, 9(1), 70-81. Recuperado de https://revistas. unimilitar.edu.co/index.php/reds/article/view/552

Chaves, M. y Barrios, L. (2017). La investigación acción y el aprendizaje por proyectos en el marco del modelo pedagógico Enseñanza para la comprensión. Experiencia del colegio Visión Mundial en comunidades vulnerables de Montería. Panorama, 11(21), 29-51.

Chiliquinga, F. y Balladares, J. (2020). Rutinas de pensamiento: Un proceso innovador en la enseñanza de la matemática. Revista Andina de Educación, 3(1), 53-63. https://doi.org/10.32719/26312816.2020.3.1.9

Domènech-Casal, J. (2019). Apuntes lingüísticos para el tránsito a la competencia científica: Leer para indagar en el aula de Ciencias. Didacticae, 5, 85-98. Recuperado de http://revistes.ub.edu/index.php/didacticae/article/viewFile/21657/pdf

Elliot, J. (2000). La investigación- acción en educación. Madrid: Morata.

Fernández, M. B. y Johnson, M. D. (2015). Investigación-acción en formación de profesores: Desarrollo histórico, supuestos epistemológicos y diversidad metodológica. Psicoperspectivas, 14(3), 93-105. Recuperado de https://www.psicoperspectivas.cl/ index.php/psicoperspectivas/article/view/626

Ferreyra, H. y Rúa, A. (2018). Dimensiones involucradas en el estudio de las prácticas de enseñanza. Revista Educación y Humanismo, 20(34), 140-155. http://dx.doi. org/10.17081/eduhum.20.34.2861

García, S. y Pérez, J. (2016). Enseñanza de las ciencias naturales en educación primaria a través de cuentos y preguntas mediadoras. $R I D H y C$, (3), 101-122. Recuperado de http://didacticahumanidadesyciencias.com/ojs/index.php/RIDHyC/article/view/46/ pdf 
Gómez, J. (2018). Competencias investigativas para el desarrollo de habilidades en el docente investigador de Educación Superior. Revista Publicando, 5(15), 465-480. Disponible en https://revistapublicando.org/revista/index.php/crv/article/view/1353

Harlen, W. (2010). Enseñanza y aprendizaje de las ciencias. Madrid: Morata.

Hernández, C. A. (2005). ¿Qué son las "Competencias Científicas"? Trabajo presentado en el Foro Educativo Nacional. Bogotá. Recuperado de http://www.acofacien.org/ images/files/ENCUENTROS/DIRECTORES_DE_CARRERA/I_REUNION_DE_ DIRECTORES_DE_CARRERA/ba37e1_QUE\%20SON\%20LAS\%20COMPETENCIAS\%20CIENTIFICAS\%20-\%20C.A.\%20Hernandez.PDF

Hernández, R., Fernández, C. y Baptista, P. (2014). Metodología de la investigación. México, D.F.: McGraw-Hill Interamericana.

ICFES. (2007). Fundamentación conceptual área de Ciencias Naturales. Bogotá, D.C.: Secretaría General, Grupo Editorial, ICFES. Recuperado de https://paidagogos.co/ pdf/fundamentacion_ciencias.pdf_

Martínez, M. (2014). Reflexiones en torno a la Investigación-Acción educativa. Revista de Investigación Educativa, 18, 58-86. Disponible en https://cpue.uv.mx/index.php/ cpue/article/view/756

Narváez, I. (2014). La indagación como estrategia en el desarrollo de competencias científicas, mediante la aplicación de una secuencia didáctica en el área de ciencias naturales en grado tercero de básica primaria. [Tesis de maestría]. Universidad Nacional de Colombia, Palmira. Disponible en http://www.bdigital.unal.edu. co/47042/1/38860365-Isabel.pdf

Ortiz-Tobón, P. y García-Rentería, W. (2019). Fortalecimiento de las competencias científicas a partir de unidades didácticas para alumnos de grado cuarto $\left(4^{\circ}\right)$ de Básica Primaria. Trilogía CienciaTecnologíaSociedad, 11(21), 149-168. https://doi. org/10.22430/21457778.1076

Páramo, P. (2011). Técnicas de recolección de información. Bogotá, D.C.: Universidad Piloto.

Paukner, F. y Sandoval, R. (2018). Aprendiendo a investigar a través de la investigación-acción. Educación y Educadores, 21(3), 504-519. https://doi.org/10.5294/ edu.2018.21.3.7

Peña, G., Cevallos, M. y Espinoza, E. (2019). Enseñanza-aprendizaje de las Ciencias Naturales en estudiantes de sexto grado de educación básica. Maestro y sociedad. Revista Electrónica para Maestros y Profesores, 16(4), 880-894. Disponible en https:// maestroysociedad.uo.edu.cu/index.php/MyS/article/view/5077

Rojas, L., Rosas, J. y Sanabria, Y. (2017). Desarrollo de la competencia de indagación en la enseñanza de las ciencias naturales en básica primaria del Instituto Técnico Ambiental San Mateo de Yopal-Casanare. [Tesis de maestría]. Universidad de La Salle, Yopal, Colombia. Recuperado de https://ciencia.lasalle.edu.co/maest_docencia_yopal/21

Samacá, I. (2015). La práctica pedagogica como lugar de legitimación del saber. Educación y territorio, 5(8), 71-86. Recuperado de https://www.jdc.edu.co/revistas/index. php/reyte/article/view/111/115 
Suárez, S. Y., Hernández, A. M., Méndez, S., Arguello, Y. R. y Garzón, N. R. (2020). La Enseñanza para la Comprensión (EpC): ruta para dinamizar los procesos de comprensión lectora en la Escuela Normal Superior de Ubaté. Infancias Imágenes, 19(1), 1-22. https://doi.org/10.14483/16579089.13873

Torres, L. y Sánchez, J. (2019). Aprendizaje activo para las ciencias naturales. Cuaderno de Política Educativa, (5), 1-12. Recuperado de http://repositorio.unae.edu.ec/ handle/56000/1212

Velásquez, S., Celis, J. y Hernández, C. (2017). Evaluación contextualizada como estrategia docente para potenciar el desarrollo de competencias matemáticas en pruebas saber. Eco matemático, 8(s1), 33-37. Recuperado de https://revistas.ufps.edu.co/index.php/ecomatematico/article/view/1377/1350

Véliz, F., Díaz, R. y Rodríguez, R. (2015). La formación de competencias científico investigativas para la sostenibilidad ambiental en el ingeniero agropecuario. REFCalE: Revista Electrónica Formación y Calidad Educativa, 2(3), 59-70. Disponible en https://refcale.uleam.edu.ec/index.php/refcale/article/view/71

Villamizar, E., Montero, M., González, M. y Castillo, M. (2019). Mejorando los niveles de comprensión en Química a partir del enfoque de la enseñanza para la comprensión. Conocimiento Educativo, 6, 37-51. https://oi.org/10.5377/ce.v6i0.8040

José Eduardo Cifuentes Garzón es Doctor en Educación y Sociedad de la Universidad de La Salle. Estudios en Alta Investigación Posdoctoral en Educación, Ciencias Sociales e Interculturalidad de la Universidad Santo Tomás. Magíster en Pedagogía, Universidad de La Sabana. Especialista en Gerencia Educativa, Corporación Universitaria Minuto de Dios. Licenciado en Educación Básica con Énfasis en Matemáticas, Humanidades y Lengua Castellana, Universidad Pedagógica y Tecnológica de Colombia. Actualmente Directivo-Docente de la Secretaría de Educación de Cundinamarca, Colombia. https:// orcid.org/0000-0002-5602-957X

Luz Marina Cortés Beltran es Licenciada en Educación Básica Primaria con Especialización en Pedagogía de la recreación y Maestría en Pegagogía becada por el Ministerio de Educación Nacional de Colombia. Actualmente, labora como docente de Basica Primaria de la Institución Educativa Departamental Ricardo González, ubicada en el municipio de Subachoque (Cundinamarca, Colombia). https://orcid.org/0000-0003-3363-7035

Nidia Yolanda Garzón Mora esta en formación docente la obtenida en la Universidad Pedagógica Nacional cuyos estudios terminó en el año 2005. Trabaja con el departamento de Cundinamarca .Maestría en pedagogía de la Universidad de la Sabana. Actualmente labora como docente de primaria en Institución Educativa Departamental Ricardo González de Subachoque (Cundinamarca, Colombia). https://orcid.org/0000-0003-0364-586X 
Diana Patricia González Pulido es Licenciada en educación con énfasis en ciencias sociales, Magister en pedagogía becada por el Ministerio Educación Nacional. Actualmente trabaja en la institución educativa departamental Ricardo González de Subachoque Cundinamarca Colombia. https://orcid.org/0000-0002-2803-6465 